\title{
$\gamma$ Irradiation of Cowpea and Potato Starch: Effect on Physicochemical Functional and Rheological Properties
}

\author{
Kush Verma ${ }^{1}$, Kulsum Jan ${ }^{2}$, Khalid Bashir ${ }^{2 *}$ \\ ${ }^{1}$ Department of Food Technology, Gautam Bhudha University, Uttar Pradesh, India; ${ }^{2}$ Department of Food Technology, Jamia \\ Hamdard University, New Delhi, India
}

\begin{abstract}
Changes in the physicochemical, thermo-rheological and antioxidant properties of the cowpea and potato starch subjected to gamma irradiation were studied. It was found that apparent amylose content, swelling index, enthalpy of gelatinization, transition temperature and total crystallinity of the starches significantly $(\mathrm{p} \leq 0.05)$ decreased with an increase in irradiation dose. Similarly, significant $(\mathrm{p} \leq 0.05)$ decline in the pasting properties (peak, trough, setback, final viscosity, and pasting temperature) for both the starches was observed with increasing the ionizing dose. On the contrary, the increased solubility index was incurred upon subjecting the starch to gamma irradiation. The irradiated starch granules remained intact showing no surface fissures. Antioxidant capacity, FRAP values, and DPPH\% inhibition, increased as the irradiation dose increases.
\end{abstract}

Keywords: DPPH inhibition; DSC; FRAP value; XRD

\section{INTRODUCTION}

Starch is naturally present as energy reserves in large quantities in plants which renders it favorable for commercial exploitation both in food and non-food industries. Starch as a food ingredient confers important properties such as providing desirable texture, consistency, structure, appearance and appeal to many food systems. Thereby, many extraction techniques for isolation of starch from plant sources have been developed throughout the decades. However, the starch in its native state exhibits certain shortcomings, viz. high retrogradation and syneresis, high viscosity even at low concentrations, low shear stress resistance, poor freeze-thaw stability, and solubility to name a few, which limits its use in many food products. Therefore, to overcome these limitations the structure and physicochemical properties of starch are modified for exploiting beneficial applications as a functional food ingredient. It is envisioned that there will be considerable demand for modified starch in the near future to meet the demanding technological needs in the food and other allied sectors. In the past few years intense research was carried out to study the modification of starch from umpteenth number of sources and reported improvements in one or more of the following properties: cold- water swelling capacity, emulsifying property, encapsulating and film formation ability, improved gelation and pasting characteristics, increased cooking characteristics, digestibility as well as increased shear tolerance, temperature, and $\mathrm{pH}$, etc. ensuring augmented benefits in food and allied industries [1-4]. In addition to these improvements, the modified starch has attracted considerable attention owing to their potential applications as dietary fat replacers and probable preventive effects against cancer, coronary heart diseases, and diverticulitis, [5-7]. Starch is widely modified by chemical and physical methods, although enzymatic and genetic modification have also been exploited. However, the enzymatic and genetic modification methods are complex and time-consuming whereas the chemical techniques, although comparatively faster, may indulge threats of leaving behind harmful residues and therefore not appropriate for food application. These concerns have directed towards preferences in adopting physical modification methods in particularly irradiation processing. This has also been accepted as suitable for modification of starches because it is a non-thermal technique, environment-friendly and economical process which has been employed for decades to bring desired changes in the physicochemical, thermal and functional properties of various food components. Irradiation

Correspondence to: Dr. Khalid Bashir, Department of Food Technology, Jamia Hamdard, New Delhi, India, E-mail: kbnaik25@gmail.com

Received: May 23, 2019; Accepted: July 10, 2019; Published: July 31, 2019

Citation: Verma K, Jan K, Bashir K (2019) $\gamma$ Irradiation of Cowpea and Potato Starch: Effect on Physicochemical Functional and Rheological Properties. J Food Process Technol 10:810.

Copyright: (C) 2019 Verma K, et al. This is an open-access article distributed under the terms of the Creative Commons Attribution License, which permits unrestricted use, distribution, and reproduction in any medium, provided the original author and source are credited. 
also helps improve the shelf life of food products as the irradiation rays can efficiently deactivate and kill bacteria, insects and other pests. Thus this technique emerges as one of the most widely accepted techniques for varied applications in the food and related industries [8-11].

Bettaïeb et al. [12] studied the impact of the gamma irradiation $(3,5,10,20$ and $50 \mathrm{kGy})$ on the physicochemical properties of starch obtained from corn. They concluded that the gelatinization temperature was decreased as the dose increased. They also found that the crystallinity of the starch was not affected up to $50 \mathrm{kGy}$, as no change in the X-ray diffraction was observed.

Lee et al. [13] studied the formation of resistant corn starch induced by gamma irradiation. Three different corn starches were selected including normal corn starch, high amylose corn starch, and waxy corn starch and irradiated at the dose rate of 5, 10, 25 and $50 \mathrm{kGy}$. The results obtained revealed that the gamma irradiation (5 kGy) induced the formation of more amylose like molecules in the starch thereby increasing the resistant starch content in each type of starch. The highest resistant starch was produced at higher doses of radiation (50 kGy). The resistant starch so produced was more in waxy corn followed by high amylose corn starch and normal corn starch. Several studies on chestnut [14]; chickpea [4]; cowpea; [15] wheat [7], buckwheat [16], rice [17] starches reported similar findings The results demonstrated decreased enthalpy, transition temperature, pasting properties (peak, trough, setback and final) and increased amylose content, reducing sugars, titrable acidity and solubility with increased dosage. The studies also revealed cracking of the starch surface when subjected to a higher dosage. In the present research, gamma irradiation-induced modifications of the various physicochemical and antioxidant properties of the cowpea and potato starches was studied in order to exploit them for diverse food and non-food applications.

\section{MATERIALS AND METHODS}

\section{Raw materials}

The cowpea seeds (Vigna unguiculata var Kashi Kanchan) and potato (Solanum tuberosum var Kufri Bahar) were procured from Dhankore market Greater Noida, Uttar Pradesh (India). The cowpea seeds were, milled and packed into airtight polyethylene pouches. All the chemicals used in this study were of analytical grade.

\section{Starch isolation}

Starch was isolated from cowpea as per the method described by Abu et al. [15]. For potato, starch was isolated as per the method described by Singh et al. [18].

\section{Gamma irradiation treatment}

All the starch samples were irradiated by $\mathrm{Co}-60$ at different doses of 5, 10, 15 and $20 \mathrm{kGy}$. The unirradiated samples of both cowpea and potato were used as control. Irradiation was done at Shri Ram Institute for Industrial Research, New Delhi, India.

\section{Swelling and solubility index}

Swelling and solubility index of the irradiated starch samples and their respective control samples were carried out at $90^{\circ} \mathrm{C}$ as given by Wani et al. [10].

\section{Pasting and rheological properties}

Pasting and rheological properties were evaluated using Rheometer (MCR 302, Anton Paar, Austria). The pasting properties were measured following the method of Wani et al. [10]. Rheological properties (hysteresis) were evaluated as per the method described by Dar et al. [16] using parallel plate geometry (diameter of $25 \mathrm{~mm}$ and with a gap of $1 \mathrm{~mm}$ ). The data obtained were fitted with Hershel-Bulkley model:

$\tau=\tau 0+K \gamma^{\cdot} n$

where $\tau$ represents shear stress $(\mathrm{Pa}), \tau 0$ measures yield stress (Pa), K represents consistency index (Pa.sn), $\mathrm{n}$ represents the flow behavior index and $\gamma^{\prime}$ is the shear rate $(s-1)$. The coefficient of thixotropic breakdown $(\mathrm{Kd})$ was determined from the equation given by Dokic et al. [19].

$\mathrm{Kd}=(\mathrm{Au}-\mathrm{Ad}) / \mathrm{Au}$

where $\mathrm{Au}$ and Ad are the integrated areas under the ascending and descending curves, respectively.

Between 2008/09 and 2015/16 domestic production decreased by $0.52 \mathrm{ml} \mathrm{T}(-8 \%)$, consumption increased by $6.75 \mathrm{ml} \mathrm{T}(48 \%)$ and import increased by $6.41 \mathrm{ml} \mathrm{T}(78 \%)$ to match the rising consumption (Figures 1 and 2).

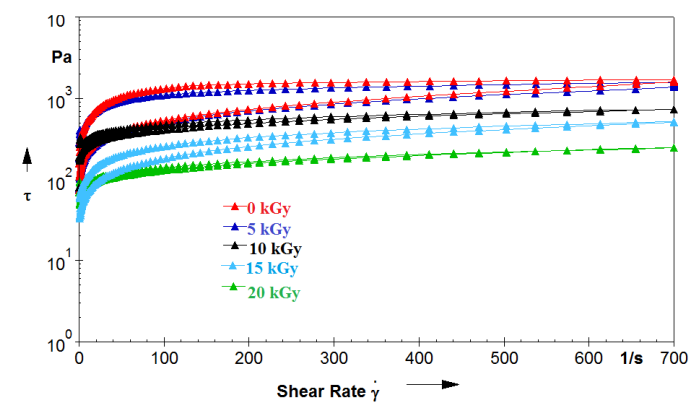

Figure 1: Hysteresis curves of unirradiated and irradiated cowpea starch.

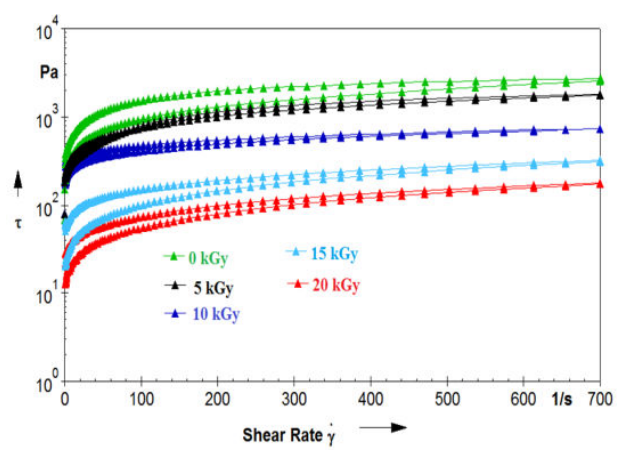

Figure 2: Hysteresis curves of unirradiated and irradiated potato starch. 


\section{Apparent amylose content (AAC)}

AAC was evaluated as per the procedure of Williams et al. [20].

\section{X-ray diffraction $(\mathrm{XRD})$}

The X-ray diffraction of the starch samples were studied as per the method reported by Hussain et al. [21].

\section{Scanning electron microscopy (SEM)}

The surface (morphological) properties of unirradiated and irradiated starch samples were analyzed by SEM (Joel JSM-7500, Joel Ltd, Tokyo Japan) as per the method described by Correia et al. [14].

\section{Thermal properties}

Gelatinization (glass transition) properties of the starch samples were evaluated as per the protocol was given by Singh et al.[18].

\section{Antioxidant properties}

The antioxidant capacity of the starch samples was evaluated by DPPH assay (\% inhibition) and Ferric Reducing Antioxidant Power (FRAP) assay according to the methods given by BrandWilliams et al. [22] and Benzie and Strain [23], respectively.

\section{Statistical analysis}

The data presented are the mean of three observations. The data were subjected to one-way ANOVA with 95\% confidence level. The variance was checked by using Duncan's test by using the statistical tool (SPSS, USA).

\section{RESULTS AND DISCUSSION}

\section{Pasting properties}

Passing parameters, viz. pasting temperature, peak (PV), trough (TV), breakdown (BV), final (FV) and setback viscosities (SV), of irradiated as well as native cowpea and potato starches, are presented in Table 1. Both the starch samples followed a similar trend showing significant $(\mathrm{p} \leq 0.05)$ decrease in pasting properties upon increasing the irradiation dose. The PV, TV, BV, FV and SV decreased from 4212 to $1332 \mathrm{cP}, 2819$ to $893 \mathrm{cP}$, 1393 to $429 \mathrm{cP}, 4028$ to $1021 \mathrm{cP}, 1209$ to $128 \mathrm{cP}$ for cowpea starch and 3820 to $987 \mathrm{cP}, 2687$ to $560 \mathrm{cP}, 1133$ to $427 \mathrm{cP}, 4012$ to $883 \mathrm{cP}$ and 1325 to $323 \mathrm{cP}$ for potato starch, respectively. Pasting temperature (PT) of cowpea and potato starch decreased significantly $(\mathrm{p} \leq 0.05)$ with increasing dose from 76.12 to $70.15^{\circ} \mathrm{C}$ and 66.37 to $60.18^{\circ} \mathrm{C}$ respectively. Similar findings were reported for bean starch [23], chickpea starch [4], wheat starch [7], rice starch [17], oat starch [16], potato starch [24]. Peak viscosity of cowpea and potato starch at $20 \mathrm{kGy}$ was decreased by $68.61 \%$ and $74.16 \%$, respectively. Peak viscosity is correlated to the swelling index of starch granules. The decrease in the peak viscosity could be credited to the depolymerization of the amylopectin chains by the breakdown of glycosidic bonds induced by irradiation which reduced the water holding capacity of the starch and thereby decreasing the swelling capacity of the granules $[16,17,23]$. The reduction in the pasting properties indicates that the food can be easily cooked with limited retrogradation. Peak viscosity has been also linked to the amylose-lipid complexing and amylose oozing propensity from starch $[4,7,24]$. BV indicates the amount of disintegration of the starch granules during cooking and is measured by taking the difference between PV and TV whereas the SV and FV indicate reorganization of the amylose fraction, i.e. retrogradation and syneresis. Therefore these parameters play a very important role in the food sector where starch is used as an additive or ingredient. Further, SV is generally used as an indicator for firmness in cooked foods, as it gives the idea of the tendency of retrogradation of a particular starch. Therefore, from Table 1 is it confirmed that ionization with gamma rays resulted in decreasing setback viscosity concluding that application of gamma-irradiated starches in foods will give products of softer texture with diminutive inclinations towards retrogradation $[9,10,25]$.

Table 1: Pasting properties of native and gamma-irradiated starches.

\begin{tabular}{|c|c|c|c|c|c|c|c|}
\hline \multirow{2}{*}{\multicolumn{2}{|c|}{$\begin{array}{l}\gamma \text { irradiation } \\
\text { dose }(k G y)\end{array}$}} & \multicolumn{6}{|c|}{ Pasting properties } \\
\hline & & $\mathrm{PV}(\mathrm{cP})$ & $\mathrm{TV}(\mathrm{cP})$ & $\mathrm{BV}(\mathrm{cP})$ & $\mathrm{FV}(\mathrm{cP})$ & $\mathrm{SV}(\mathrm{cP})$ & $\mathrm{PT}\left({ }^{\circ} \mathrm{C}\right)$ \\
\hline \multicolumn{8}{|c|}{ Cowpea starch } \\
\hline 0 & \multicolumn{2}{|c|}{$4212 \pm 28.14^{\mathrm{a}}$} & $2819 \pm 21.20^{\mathrm{a}}$ & $1393 \pm 14.30^{\mathrm{a}}$ & $4028 \pm 18.12^{\mathrm{a}}$ & $1209 \pm 9.68^{\mathrm{a}}$ & $76.12 \pm 0.58^{a}$ \\
\hline 5 & \multicolumn{2}{|c|}{$3615 \pm 18.38^{b}$} & $2534 \pm 15.71^{b}$ & $1081 \pm 8.81^{b}$ & $3247 \pm 14.37^{\mathrm{b}}$ & $713 \pm 6.30^{b}$ & $75.38 \pm 0.61^{\mathrm{ab}}$ \\
\hline 10 & \multicolumn{2}{|c|}{$2431 \pm 12.25^{c}$} & $1646 \pm 12.30^{c}$ & $785 \pm 5.67^{c}$ & $2234 \pm 16.33^{c}$ & $588 \pm 7.51^{c}$ & $75.00 \pm 0.42^{b}$ \\
\hline 15 & \multicolumn{2}{|c|}{$1842 \pm 10.64^{\mathrm{d}}$} & $1138 \pm 9.66^{\mathrm{d}}$ & $704 \pm 6.31^{\mathrm{d}}$ & $1369 \pm 10.37^{\mathrm{d}}$ & $231 \pm 5.64^{\mathrm{d}}$ & \\
\hline 20 & \multicolumn{2}{|c|}{$1322 \pm 9.55^{\mathrm{e}}$} & $893 \pm 5.64^{e}$ & $429 \pm 7.33^{\mathrm{e}}$ & $1021 \pm 9.91^{\mathrm{e}}$ & $128 \pm 4.41^{\mathrm{e}}$ & $70.15 \pm 0.14^{d}$ \\
\hline
\end{tabular}

Potato starch 


\begin{tabular}{lcccccc}
\hline 0 & $3820 \pm 12.34^{\mathrm{a}}$ & $2687 \pm 21.02^{\mathrm{a}}$ & $1133 \pm 10.24^{\mathrm{a}}$ & $4012 \pm 22.31^{\mathrm{a}}$ & $1325 \pm 12.34^{\mathrm{a}}$ & $66.37 \pm 0.22^{\mathrm{a}}$ \\
\hline 5 & $2716 \pm 17.33^{\mathrm{b}}$ & $1831 \pm 15.30^{\mathrm{b}}$ & $885 \pm 11.10^{\mathrm{b}}$ & $2653 \pm 14.55^{\mathrm{b}}$ & $822 \pm 12.15^{\mathrm{b}}$ & $64.34 \pm 0.34^{\mathrm{b}}$ \\
\hline 10 & $1866 \pm 19.34^{\mathrm{c}}$ & $1236 \pm 12.21^{\mathrm{c}}$ & $630 \pm 6.40^{\mathrm{c}}$ & $1721 \pm 11.10^{\mathrm{c}}$ & $485 \pm 4.66^{\mathrm{c}}$ & $64.00 \pm 0.19^{\mathrm{b}}$ \\
\hline 15 & $1234 \pm 10.21^{\mathrm{d}}$ & $711 \pm 6.67^{\mathrm{d}}$ & $523 \pm 5.20^{\mathrm{d}}$ & $1053 \pm 10.07^{\mathrm{d}}$ & $342 \pm 6.34^{\mathrm{d}}$ & $62.11 \pm 0.45^{\mathrm{c}}$ \\
\hline 20 & $987 \pm 6.31^{\mathrm{e}}$ & $560 \pm 7.51^{\mathrm{e}}$ & $427 \pm 7.31^{\mathrm{e}}$ & $883 \pm 8.02^{\mathrm{e}}$ & $323 \pm 3.74^{\mathrm{e}}$ & $60.18 \pm 0.51^{\mathrm{d}}$ \\
\hline
\end{tabular}

\section{Rheological properties}

Figures 1 and 2 demonstrate the hysteresis curves of the native and irradiated cowpea and potato starches. Herschel-Bulkely model was used to obtain different rheological parameters and presented in Table 2. Increasing the irradiation dose from 0-20 $\mathrm{kGy}$ decreased the yield stress ( $\tau 0$ ) and consistency index K of both cowpea and potato starches. The $\tau 0$ decreased from 51.12 to 10.24 and 39.41 to $9.34 \mathrm{~Pa}$ for cowpea and potato starch, respectively. The $\mathrm{K}$ of cowpea starch decreased from 31.25 to 6.71 $\mathrm{Pa}$ sn whereas potato starch declined from 30.11 to $6.38 \mathrm{~Pa}$ sn. Further, it was observed that increasing shear rate resulted in a decreasing trend in viscosity indicating a non-Newtonian behavior. The irradiated starch samples demonstrated a larger reduction in viscosity values than control samples which was dose-dependent. The flow behavior index of less than one indicates the shear-thinning behavior of the gel $[11,26]$. From Figures 1 and 2 it is apparent that the hysteresis curves (ascending and descending) displayed pseudoplastic behavior as the descending curve also revealed a concave shape, typical to shear-thinning materials. The flow curves obtained from the native and irradiated starches presented differences in hysteresis pattern. For the evaluation and classification of the thixotropy (time-dependent shear thinning) behavior, the coefficient of the thixotropic breakdown (Kd) was calculated using Eq. 2. $\mathrm{Kd}$ measures the required energy to spifflicate the starch gel structure. Results obtained showed significant $(\mathrm{p} \leq 0.05)$ decrease in the Kd values, from 0.31 to 0.09 and 0.29 to 0.10 for cowpea and potato starch respectively, which is again dosedependent as the highest values were obtained for native starches and least values when subjected to $20 \mathrm{kGy}$. The decreasing trend in the $\mathrm{Kd}$ values may be accredited to the structural disruption in the starch chains which is intensified upon higher doses of irradiation [3]. The findings revealed that un-irradiated starch had the highest structural strength which is validated by the pasting properties, swelling index and consistency index $(\mathrm{K})$ obtained. The results here obtained were in agreement with those of Bashir et al. [11], Dar et al. [16], Kumar et al. [17] and Lawal et al. [27].

Table 2: Rheological parameters of native and irradiated starches.

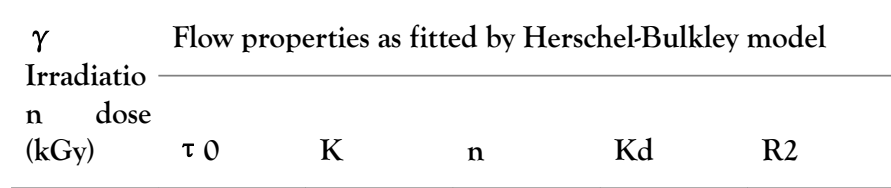

Cowpea starch

\begin{tabular}{llllll}
\hline 0 & 51.12 & 31.25 & 0.32 & 0.31 & 0.99 \\
\hline 5 & 46.31 & 22.37 & 0.38 & 0.28 & 0.98 \\
\hline 10 & 26.15 & 14.28 & 0.46 & 0.15 & 0.99 \\
\hline 15 & 18.33 & 10.33 & 0.48 & 0.14 & 0.99 \\
\hline 20 & 10.24 & 6.71 & 0.61 & 0.09 & 0.98 \\
\hline
\end{tabular}

Potato starch

\begin{tabular}{llllll}
\hline 0 & 39.41 & 30.11 & 0.33 & 0.29 & 0.99 \\
\hline 5 & 32.14 & 18.24 & 0.38 & 0.24 & 0.99 \\
\hline 10 & 26.87 & 15.33 & 0.44 & 0.19 & 0.97 \\
\hline 15 & 18.62 & 10.24 & 0.52 & 0.16 & 0.98 \\
\hline 20 & 9.34 & 6.38 & 0.63 & 0.1 & 0.99 \\
\hline
\end{tabular}

\section{Antioxidant properties}

Figures 3 and 4 denote the DPPH scavenging capacity and FRAP values of the native and irradiated cowpea and potato starch samples. Both assays depict that the antioxidant properties of both starches increased with increasing dose. For native cowpea starch, $26 \%$ DPPH inhibition was found, which increased to $31,38,39$ and $43 \%$ upon increasing the dose from 5-20 kGy, respectively. The FRAP value of cowpea starch increased in a similar manner with least value exhibited for native starch $(0.22 \mathrm{mmol} / 100 \mathrm{~g})$ which increased significantly $(\mathrm{p}$ $\leq 0.05$ ) to $0.26,0.34,0.36 \mathrm{mmol} / 100 \mathrm{~g}$ starch at doses of 5,10 and $15 \mathrm{kGy}$. However, FRAP value decreased to $0.32 \mathrm{mmol} / 100$ $\mathrm{g}$ when subjected to $20 \mathrm{kGy}$. In a similar view, DPPH inhibition of potato starch was found to be $22 \%$ in its native form which increased to $28 \%$ and $36 \%$ at doses 5 and $10 \mathrm{kGy}$. However, at doses 15 and $20 \mathrm{kGy}$, it decreased to $34 \%$ and $31 \%$ respectively, still higher as compared to control. Similarly, FRAP values increased with dose, with the lowest value $(0.20 \mathrm{mmol} / 100 \mathrm{~g})$ for native and the highest value $(0.38 \mathrm{mmol} / 100 \mathrm{~g})$ for $15 \mathrm{kGy}$ treated starch. At $20 \mathrm{kGy}$ FRAP value of potato starch decreased to $0.33 \mathrm{mmol} / 100 \mathrm{~g}$ of starch. The increase in DPPH inhibition observed in irradiated starches resulted due to the formation of new double bonds owing to radiation degradation which henceforth reduced the reactivity of free radicals. These findings were in agreement with those of Hussain et al. [21], Choi et al. [27], and Mustapha et al. [28]. Oufedjikh et al. [29] reported that 
citrus peel irradiated with low dose could boost the production of total phenolic compounds. Further Zhu et al. [30] postulated that gamma irradiation may induce modification of some enzymes in rice resulting in the higher forms of phenolic compounds.

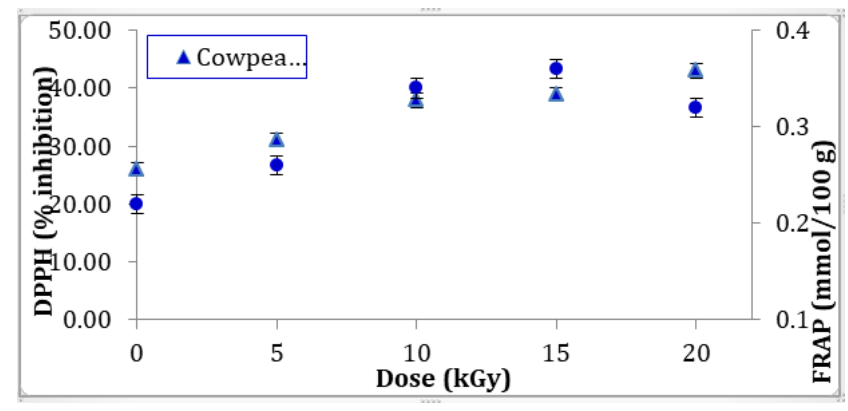

Figure 3: DPPH and FRAP of native and irradiated cowpea starches.

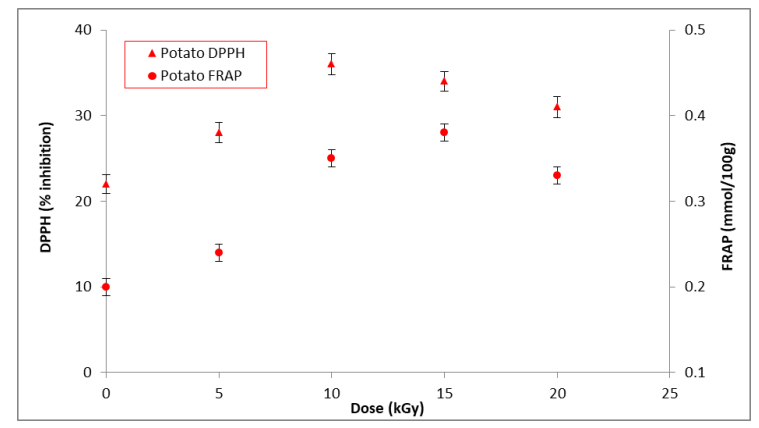

Figure 4: DPPH and FRAP of native and irradiated potato starches.

\section{Swelling and solubility index}

Table 3 represents the swelling solubility indices of un-irradiated and irradiated cowpea and potato starches. The swelling index was observed to significantly $(\mathrm{p} \leq 0.05)$ decrease with increasing dose. In native cowpea starch highest swelling index (15.22 g) was found. Similarly, for potato starch maximum swelling index (17.23 g) was obtained for native starch. The reduced swelling index demonstrated in irradiated starched may be ascribed to the impact of irradiation on the destruction of amylopectin which is principally responsible for swelling in starches. Furthermore, on increasing the temperature the diffusion of water was prevented by gelatinized starch and denatured protein matrix $[4,7,16,17]$.

On a different note, the solubility index was increased with increasing irradiation dose. It was found that increasing the dose significantly ( $\mathrm{p} \leq 0.05$ ) increased the solubility index from $13.13 \%$ to $31.07 \%$ and $11.10 \%$ to $29.43 \%$ for cowpea and potato starch, respectively. The improved solubility obtained may be accounted to the cleaving of glycosidic bonds by irradiation thereby breaking down the starches (amylopectin branches) to form simple sugars that have a higher affinity for water as compared to starch and disruption of inter-and intrahydrogen bonds leading to increased polarity $[3,12,31]$.

Table 3: Swelling index, solubility index and AAC of native and irradiated starches.

Gamma irradiation dose (kGy)

\begin{tabular}{|c|c|c|c|c|c|}
\hline \multirow[b]{2}{*}{ Parameters } & \\
\hline & 0 & 5 & 10 & 15 & 20 \\
\hline \multicolumn{6}{|l|}{ Cowpea starch } \\
\hline Swelling index $(\mathrm{g} / \mathrm{g})$ & $15.22 \pm 0.43^{\mathrm{a}}$ & $12.10 \pm 0.34^{b}$ & $9.41 \pm 0.31^{c}$ & $6.80 \pm 0.22^{\mathrm{d}}$ & $5.33 \pm 0.20^{e}$ \\
\hline Solubility index (\%) & $13.13 \pm 0.42^{\mathrm{e}}$ & $19.38 \pm 0.36^{\mathrm{d}}$ & $26.37 \pm 0.16^{c}$ & $28.03 \pm 0.66^{b}$ & $31.07 \pm 0.43^{\mathrm{a}}$ \\
\hline AAC (\%) & $26.31 \pm 0.43^{\mathrm{a}}$ & $24.37 \pm 0.12^{b}$ & $21.30 \pm 0.41^{\mathrm{c}}$ & $19.48 \pm 0.20^{d}$ & $18.22 \pm 0.09^{\mathrm{e}}$ \\
\hline \multicolumn{6}{|l|}{ Potato starch } \\
\hline Swelling index $(\mathrm{g} / \mathrm{g})$ & $17.23 \pm 0.13^{\mathrm{a}}$ & $15.18 \pm 0.61^{b}$ & $11.29 \pm 0.22^{c}$ & $7.11 \pm 0.38^{d}$ & $4.30 \pm 0.33^{e}$ \\
\hline Solubility index (\%) & $11.10 \pm 0.45$ & $14.37 \pm 0.41^{b}$ & $18.43 \pm 0.36^{c}$ & $24.31 \pm 0.43^{\mathrm{d}}$ & $29.43 \pm 0.40^{e}$ \\
\hline $\mathrm{AAC}(\%)$ & $27.01 \pm 0.12^{\mathrm{a}}$ & $22.11 \pm 0.44^{b}$ & $19.18 \pm 0.24^{c}$ & $18.68 \pm 0.46^{c}$ & $16.11 \pm 0.11^{d}$ \\
\hline
\end{tabular}

Values expressed are means $\pm \operatorname{SD}(n=3)$

Means in the rows with different superscripts are significantly different $(\mathrm{p} \leq 0.05)$

\section{Apparent amylose content}

In a similar manner as in swelling index, the Apparent Amylose Content (AAC) of both starches was significantly $(\mathrm{p} \leq 0.05)$ decreased upon increasing the irradiation dose to $20 \mathrm{kGy}$ (Table 3). The AAC for native cowpea and potato starch was found to be $26.31 \%$ and $27.01 \%$, respectively. AAC decreased to $18.22 \%$ and $16.11 \%$ for cowpea and potato starch, respectively, at doses 
of $20 \mathrm{kGy}$. These results were in close consistent with findings of Wani et al. [10] Yu and Wang [32]. The reduced AAC of irradiated starched may be accredited to randomized scission of the linear chain amylose fraction incurred due to ionization resulting in oligomers formation which consequently decreases the iodine binding ability of the samples $[3,16,17]$. In a different vein, Yu and Wang [32] assumed that reduction of AAC in irradiated starches may originate from the cleaving of partly branched long chains in amylopectin.

\section{Thermal properties}

Table 4 represents the thermal properties of cowpea and potato starches subjected to ionization. The transition (onset, peak, and conclusion) temperatures, representing the gelatinization temperature range of the starch samples, decreased significantly ( $p \leq 0.05$ ) on increasing the irradiation dose. The decreasing trend could be attributed to the damage of weaker crystalline structures. For cowpea starch onset, peak and conclusion temperatures significantly $(\mathrm{p} \leq 0.05)$ declined from $(72.20-67.76)^{\circ} \mathrm{C}, \quad 74.64$ to $71.11{ }^{\circ} \mathrm{C}$ and 77.12 to $74.04{ }^{\circ} \mathrm{C}$ respectively with an increase in dose. Similar declination in transition temperatures was also observed in potato starch. These findings were in consistent with previous studies in chickpea flour [33]; chickpea starch [4,15]; rice starch [34]; wheat flour [11]; wheat starch [35]. The decreasing trend observed in the transition temperatures and enthalpy of gelatinization can be accounted to the breakdown of amylopectin chains into smaller units as the glycosidic linkages are cleaved and thereby diminution in the overall crystallinity $[4,22]$. Peak temperature and enthalpy measures the crystallinity quality and overall crystallinity of starch, respectively, and the observed declination in these parameters indicate a gradual decline in the percent crystallinity of the starch. The reduction trend in the enthalpy is attributed to the increased disruption of the double helices of the starch upon irradiation [32]. These findings were validated by the XRD results.

Table 4: Thermal properties of native and irradiated starches.

\section{$\gamma$ irradiation dose}

(kGy)

c

0

5

10

15

20

Cowpea starch

\begin{tabular}{lccccc}
\hline To $\left({ }^{\circ} \mathrm{C}\right)$ & $72.20 \pm 0.32^{\mathrm{a}}$ & $71.53 \pm 0.27^{\mathrm{b}}$ & $71.10 \pm 0.43^{\mathrm{b}}$ & $68.57 \pm 0.35^{\mathrm{c}}$ & $67.76 \pm 0.28^{\mathrm{d}}$ \\
\hline $\mathrm{Tp}\left({ }^{\circ} \mathrm{C}\right)$ & $74.64 \pm 0.28^{\mathrm{a}}$ & $74.62 \pm 0.32^{\mathrm{a}}$ & $74.10 \pm 0.30^{\mathrm{ab}}$ & $73.63 \pm 0.24^{\mathrm{b}}$ & $71.11 \pm 0.15^{\mathrm{c}}$ \\
\hline $\mathrm{Tc}\left({ }^{\circ} \mathrm{C}\right)$ & $77.12 \pm 0.22^{\mathrm{a}}$ & $76.10 \pm 0.23^{\mathrm{b}}$ & $75.75 \pm 0.09^{\mathrm{c}}$ & $75.24 \pm 0.10^{\mathrm{d}}$ & $74.04 \pm 0.44^{\mathrm{e}}$ \\
\hline$\Delta \mathrm{H}(\mathrm{J} / \mathrm{g})$ & $6.62 \pm 0.29^{\mathrm{a}}$ & $6.10 \pm 0.18^{\mathrm{b}}$ & $5.40 \pm 0.11^{\mathrm{c}}$ & $4.89 \pm 0.21^{\mathrm{d}}$ & $3.17 \pm 0.31^{\mathrm{e}}$ \\
\hline
\end{tabular}

Potato starch

\begin{tabular}{lccccc}
\hline To $\left({ }^{\circ} \mathrm{C}\right)$ & $67.61 \pm 0.25^{\mathrm{a}}$ & $67.48 \pm 0.21^{\mathrm{a}}$ & $66.00 \pm 0.37^{\mathrm{b}}$ & $65.10 \pm 0.44^{\mathrm{c}}$ & $64.77 \pm 0.24^{\mathrm{d}}$ \\
\hline $\mathrm{Tp}\left({ }^{\circ} \mathrm{C}\right)$ & $69.00 \pm 0.22^{\mathrm{a}}$ & $68.80 \pm 0.22^{\mathrm{a}}$ & $68.00 \pm 0.18^{\mathrm{b}}$ & $67.64 \pm 0.10^{\mathrm{c}}$ & $66.10 \pm 0.31^{\mathrm{d}}$ \\
\hline Tc $\left({ }^{\circ} \mathrm{C}\right)$ & $73.18 \pm 0.14^{\mathrm{a}}$ & $71.45 \pm 0.33^{\mathrm{b}}$ & $70.34 \pm 0.14^{\mathrm{c}}$ & $69.12 \pm 0.34^{\mathrm{d}}$ & $68.19 \pm 0.15 \mathrm{e}$ \\
\hline$\Delta \mathrm{H}(\mathrm{J} / \mathrm{g})$ & $5.91 \pm 0.19^{\mathrm{a}}$ & $5.46 \pm 0.10^{\mathrm{b}}$ & $5.14 \pm 0.17^{\mathrm{c}}$ & $4.67 \pm 0.21^{\mathrm{d}}$ & $2.15 \pm 0.11^{\mathrm{e}}$ \\
\hline
\end{tabular}

Values expressed are means $\pm \operatorname{SD}(n=3)$

Means in the rows with different superscripts are significantly different $(p=0.05)$

\section{X-ray diffraction}

Figure 5 demonstrates the X-ray diffraction patterns of the cowpea and potato starches subjected to irradiation dose from 0 to $20 \mathrm{kGy}$. The cowpea starch revealed peaks at 15.210, 17.240, $18.20,20.180,23.20026 .580$ and 32.900 whereas the potato starch showed peaks at 11.470, 15.250, 16.950, 17.250, 17.450, $19.560,22.310,24.210,26.480$ and $31.690,34.510$. The crystallinity of both starches demonstrated a declining trend with increasing dose where un-irradiated cowpea starch showed crystallinity of $22.58 \%$ which decreased to $21.51 \%$ and $20.89 \%$ for $10 \mathrm{kGy}$ and $20 \mathrm{kGy}$, respectively. Similarly, the crystallinity of the un-irradiated potato starch was $19.78 \%$, which was found to decrease to $18.19 \%$ and $17.14 \%$ when treated with $10 \mathrm{kGy}$ and $20 \mathrm{kGy}$, respectively. Gamma irradiation resulted in decreased in peak intensities resulting in decreased\% crystallinity of the starches which can be ascribed to the disruption of the organized amylopectin structure and double helices in the starch granules. The decreasing trend in the relative crystallinity by higher doses of gamma irradiation resulted in decreasing enthalpy of gelatinization. These results 
are in consistency with the findings of Bashir and Aggarwal [4], Chung and Liu [36] and Ciesla et al. [37].
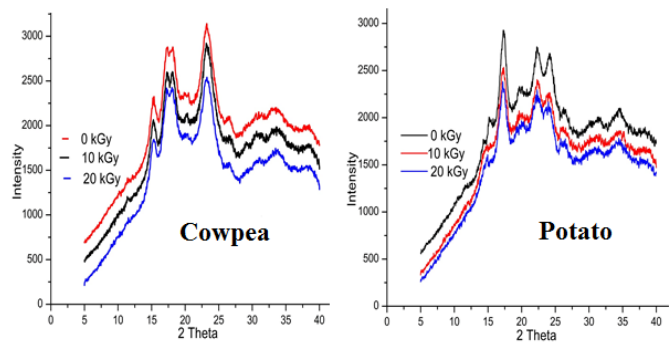

Figure 5: XRD pattern of native and irradiated cowpea and potato starch.

\section{Scanning electron microscopy}

The SEM images of the cowpea and potato starches subjected to irradiation at 0 to $20 \mathrm{kGy}$ are given in Figure 6. The SEM images of cowpea displayed several shapes of the granules (oval, kidney, round) with an average size of $17.91 \mu \mathrm{m}$. The surface was smooth with no fissures or splitting in irradiated granules. Oval and spherical starch granules with an average size of $22.55 \mu \mathrm{m}$ were observed in both unirradiated and irradiated potato starches samples. Abu et al. [15] also reported there was no physical damage to irradiated starches by gamma irradiation. It can be concluded that irradiation-induced the structural change without any physical damage to starch granules [4,32].

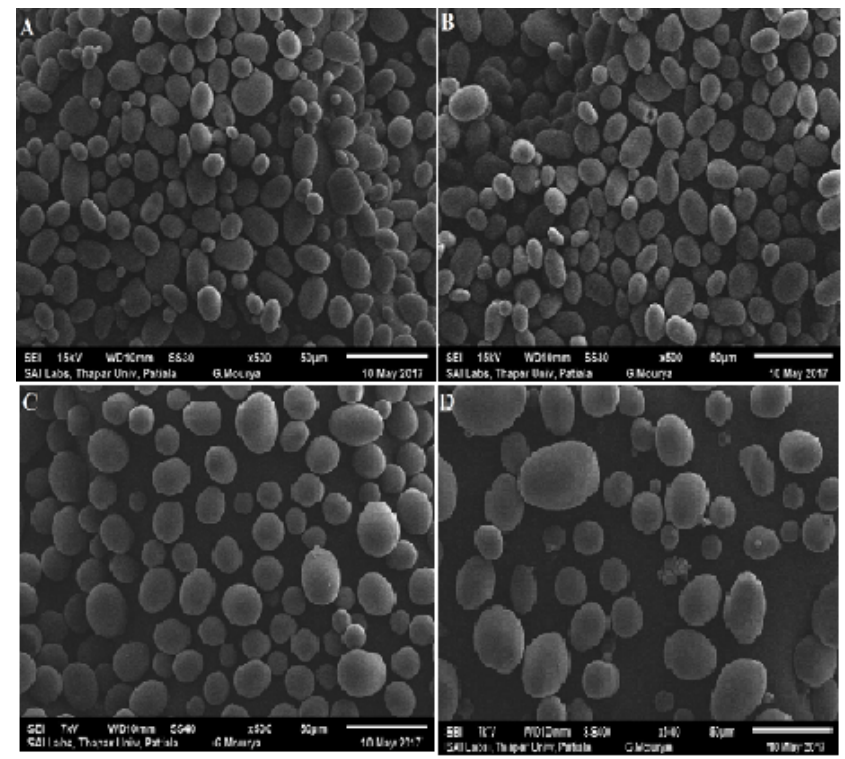

Figure 6: Scanning electron images of native and $20 \mathrm{kGy}$ treated starches (A: native cowpea; B: $20 \mathrm{kGy}$ cowpeas; C: native potato; D: 20 $\mathrm{kGy}$ potato).

\section{CONCLUSION}

Gamma irradiation resulted in a decrease in total crystallinity of the cowpea and potato starch. However, there was no physical damage induced to the granules as no fissures were seen. Irradiation caused a decreased in AAC, swelling index and pasting properties. But on the contrary, the solubility index was greatly improved when subjected to irradiation which increased with increasing dose. Gamma irradiation also modified the functional properties of the starch, viz. decreased gelatinization enthalpy and retrogradation. Therefore, unlike the other physical methods which cause adverse physical changes to the starches and chemical methods which incur toxicological hazards, irradiation proves as a beneficial method for inducing controlled modification of starches for various application in the food and other related industries.

\section{REFERENCES}

1. Shi X, BeMiller JN. Effect of sulfate and citrate salts on derivatization of amylose and amylopectin during hydroxylpropylation of corn starch. Carbohydrate Polymers. 2000;43:333-6.

2. Tester RF, Karkalas J, Qi X. Starch structure and digestibility: enzyme-substrate relationship. Worlds Poul Sci. 2004;60:186-95.

3. Bashir K, Aggarwal M. Effects of gamma irradiation on the physicochemical, thermal and functional properties of chickpea flour. LWT-Food Sci Tech. 2016;69:614-622.

4. Bashir, K, Aggarwal M. Physicochemical, thermal and functional properties of gamma irradiated chickpea starch. Int J Biol Macro. 2017;97:426-433.

5. Asp NG, Bjorck I. Trends in food science and technology. Resistant Starch. 1992;3:111-4.

6. Lopez HW, Levrat-Werny MA, Coudray C, Besson C, Krespine V, Message A, et al. Class 2 resistant starch lower plasma and liver lipid levels and improve mineral retention in rats. J Nutr. 2001;131:1283-1289.

7. Bashir K, Swer TL, Prakash KS, Aggarwal M. Physico-chemical and functional properties of gamma irradiated whole wheat flour and starch. LWT-Food Sci Technol. 2017;76:131-139.

8. Kaur B, Ariffin F, Bhat R, Karim A. Progress in starch modification in the last decade. Food Hyrdocolloids. 2012;26:398-404.

9. Bashir K, Aggarwal M. Effects of gamma irradiation on cereals and pulses- A review. Int J Recent Sci Res. 2016;7(12):14680-14686.

10. Wani IA, Jabeen M, Geelani H, Masoodi FA, Saba I, Muzaffar S. Effect of gamma irradiation on physicochemical properties of Indian Horse Chestnut (Aesculus indica Colebr.) starch. Food Hydrocolloids. 2014;35:253-263.

11. Bashir K, Jan K, Aggarwal M. Thermo-rheological and functional properties of gamma irradiated whole wheat flour. International Journal of Food Science and Technology. 2017;52(4):927-935.

12. Bettaieb NB, Jerbi MT, Ghorbel D. Gamma radiation influences pasting, thermal and structural properties of corn starch. Radiation Physics and Chemistry. 2014;103:1-8.

13. Lee JS, Ee ML, Chung KH, Othman Z. Formation of resistant corn starches induced by gamma-irradiation. Carbohydrate Polymers. 2013;97:14-617.

14. Correia P, Cruz LL, Beirao-da-Costa L. Morphology and structure of chestnut starch isolated by alkali and enzymatic methods. Food Hydrocolloids. 2012;28:313-319.

15. Abu JO, Duodu KG, Minnaar A. Effect of gamma irradiation on some physicochemical and thermal properties of cowpea (Vigna unguiculata L.) starch. Food Chem. 2006;95:386-393.

16. Dar MZ, Deepika K, Jan K, Swer TL, Kumar P, Verma R, et al. Modification of structure and physicochemical properties of buckwheat and oat starch by $\gamma$-irradiation. Int J Biol Macromol. 2017;108:1348-1356.

17. Kumar P, Prakash KS, Jan K, Swer TL, Jan S, Verma R, et al. Effects of gamma irradiation on starch granule structure and 
physicochemical properties of brown rice starch. J Cereal Sci. 2017;77:194-200.

18. Singh S, Singh N, Ezekiel R, Kaur A. Effects of gamma-irradiation on the morphological, structural, thermal and rheological properties of potato starches. Carbohydrate Polymers. 2011;83:1521-1528.

19. Dokic L, Dapcevic T, Krstonosic V, Dokic P, Hadnadev M. Rheological characterization of corn starch isolated by alkali method. Food Hydrocolloids. 2010;24:172-177.

20. Williams PC, Kuzina FD, Hlynka I. A rapid colorimetric procedure for estimating amylose content of starches and flours. Cereal Chem.1970;47:411-420.

21. Hussain PR, Wani IA, Suradkar PP, Dar MA. Gamma irradiation induced modification of bean polysaccharides: Impact on physicochemical, morphological and antioxidant properties. Carbohydrate Polymers. 2014;110:183-194.

22. Brand WW, Cuvelier ME, Berset C. Use of a free radical method to evaluate antioxidant activity. Food Sci Technol. 1995;28:25-30.

23. Benzie IF, Strain JJ. The ferric reducing ability of plasma (FRAP) as a measure of "antioxidant power": the FRAP assay. Anal Biochem. 1996;239(1):70-76.

24. Liu Q, Weber E, Currie V, Yada R. Physicochemical properties of starches during potato growth. Carbohydrate Polymers. 2003;51(2):213-221.

25. Chan H, Leh CP, Bhat R, Senan C, Williams PA, Karim AA. Molecular structure, rheological and thermal characteristics of ozone-oxidized starch. Food Chemistry. 2011;126(3):1019-1024.

26. Lawal OS, Lapasin $\mathrm{R}$, Bellich $\mathrm{B}$, Olayiwola TO, Cesàro $\mathrm{A}$, Yoshimura $\mathrm{M}$, et al. Rheology and functional properties of starches isolated from five improved rice varieties from West Africa. Food Hydrocolloids. 2011;25:1785-1792.

27. Choi JI, Kim JK, Srinivasan P, Kim JH, Park HJ, Byun MW, et al. Comparison of gamma ray and electron beam irradiation on extraction yield, morphological and antioxidant properties of polysaccharides from tamarind seed. Radiat. Phy Chem. 2009; 78:605-609.

28. Mustapha MB, Bousselmi M, Jerbi T, Bettaïebb NB, Fattoucha S. Gamma radiation effects on microbiological, physicochemical and antioxidant properties of Tunisian millet (Pennisetum glaucum). Food Chem. 2014;154:230-237.

29. Oufedjikh H, Mahrouz M, Amiot MJ, Lacroix M. Effect of $\gamma$ Irradiation on phenolic compounds and phenylalanine ammonialyase activity during storage in relation to peel injury from peel of citrus clementina hort. J Agri Food Chem. 2000;48(2):559-565.

30. Zhu F, Cai YZ, Bao J, Corke H. Effect of gamma-irradiation on phenolic compounds in rice grain. Food Chem. 2010;120(1):74-77.

31. Liu T, Ma Y, Xue S, Shi J. Modification of structure and physicochemical properties of maize starch by gamma irradiation treatments. LWT-Food Sci Technol. 2012;46:156-163.

32. Yu Y, Wang J. Effect of gamma ray irradiation on starch granule structure and physicochemical properties of rice. Food Res Int. 2007;40:297-303.

33. Verma R, Jan S, Rani S, Jan K, Swer TL, Prakash KS, et al. Physicochemical and functional properties of gamma irradiated buckwheat and potato starch. Radiat Phy Chem. 2018;144:37-42.

34. Bao J, Ao Z, Jane J. Characterization of physical properties of flour and starch from gamma irradiated white rice. Starch. 2005;57:480-487.

35. Ciesla K, Eliasson AC. DSC studies of gamma irradiation influence on gelatinization and amylose lipid complex transition occurring in wheat starch. Radiat Phys Chem. 2003;68:933-940.

36. Chung HJ, Liu Q. Molecular structure and physicochemical properties of potato and bean starches as affected by gamma irradiation. Int J Biol Macromol. 2010;47:214-222.

37. Ciesla K, Zoltowski T, Mogilevsky LY. Detection of starch transformation under gamma irradiation by small angle X-ray scatting. Starch/Starke. 1991;43:11-16. 